Jogging not running: A narrative approach to exploring 'exercise as leisure' after a life in elite football

Dr Luke Jones - University of Hull

Professor Jim Denison - University of Alberta

This is an Accepted Manuscript of an article published by Taylor \& Francis in Leisure studies on 05 Sep 2019, available online: https://www.tandfonline.com/doi/full/10.1080/02614367.2019.1662831 


\begin{abstract}
As research has shown, former elite athletes often struggle to adapt to aspects of their postsport lives. This can include the management of their identities, dealing with the uncertainty of their new roles, and negotiating the changes that occur to their bodies. In this paper we discuss an under-reported challenge facing retired athletes: how to manage their ongoing relationship with exercise. To address this issue we adopted a narrative approach, based on the first author's experiences as a former football player, to provide a socio-cultural reading of the various challenges involved in the transition from exercise as a vocation to a leisure activity. We suggest that these stories demonstrate that in retirement, former athletes' docility, while seemingly advantageous, can also be a significant obstacle to developing alternative meanings for exercise, including as a potential re-creative or leisure activity that can become meaningful and important in its own right.
\end{abstract}




\section{Jogging not running: A narrative approach to exploring 'exercise as leisure' after a life in elite football}

For those who have been elite athletes, the greater part of their biography is their postsports life, during which they may experience manifold ramifications associated with the ‘complex problem' of the distancing from their previous athletic incarnation (Fleuriel \& Vincent, 2009). These 'ramifications' include a number of challenging circumstances (Blinde \& Stratta, 1992) that are commonly associated with athletes’ interrupted selves (Hickey \& Kelley, 2008), the fear of facing an uncertain future without their sport (Roderick, 2006), and the changes that occur in their physical bodies and dietary habits (McMahon, Penney, \& Dinan-Thompson, 2012). Hill and Lowe (1974) remarked that, the retiring athlete can still be considered able bodied, but whether he/she employs his/her physical abilities or dissipates them is questionable. In line with this comment, we suggest that beyond the work of Tracey and Elcombe (2004), an under-reported challenge presented to retiring athletes is managing their on-going relationship with exercise after they leave their sport. In this paper, therefore, we consider how retired athletes experience their re-orientation to exercise and what, if any, challenges come with the shift in viewing exercise as a function of a specialised vocation to an element of one’s leisure.

In addressing these points, like Tsang (2000), we use narrative as a way of writing and analysing the complexities inherent in the sport, exercise, leisure transition that has become a growing phenomena in sport today. More specifically, the stories we present, based on the first author's experiences as a former football player, provide a socio-cultural reading of the various challenges involved in the transition from exercise as a vocation to a leisure activity. In this way, we aim to marry social theory, in particular Foucault's (1991) analysis of discipline, with narrative representation, in an attempt to "problematize through an intentional interaction between theory and expression” (Denison, 2016, p. 9). 


\section{'Exercise as Work' in Football}

The first author used to be a full-time Association footballer (footballer) at a modestly high level in the United Kingdom. From the age of 10 years old, for almost a decade, he trained twice a day and played a ninety-minute match at least twice a week. Alongside these organised sessions he did all manner of physical exercises associated with attempting to be better prepared for the activity of football, including extra running sessions and following a detailed strength and conditioning program. Before this organised lifestyle, when he was a little boy, he chased a football around his garden, and at the same time, he was exercising, recreating, and experiencing football as a leisure activity. As he grew to be a young man, however, the element of play or leisure was overshadowed, or side-lined, and exercise became a central component of an exclusive vocation: becoming a footballer. Any 'fun' he had was appropriated by his coaches, and carefully choreographed into his daily routine (Avner, Denison, \& Markula, 2019). As football became his work, he became a "highly skilled manual labourer” (Roderick, 2006), and in this way, his exercise routines connected to football became a highly functional activity.

This scenario is unsurprising given that football has historically been a working environment within which a certain section of the British populace, predominantly the working class, has been the target of a ‘disciplinary’ agenda (Hughson, 2009). Hughson has revealed how the production of modernist pursuits such as football helped with the 'disciplining' of the working class in industrial Britain throughout the $19^{\text {th }}$ and early $20^{\text {th }}$ century. As a result of the modernisation of British society, football, in its various guises, was taken from the countryside and civilised during the industrial era of the $19^{\text {th }}$ century. Within a few decades, bolstered by the blossoming ethos of public school amateurism, codified football emerged out of the British public school system because of its perceived capacity to build character and to teach the values of leadership, loyalty and discipline (Giulianotti, 
1999). This preparatory ethos replaced an emphasis based purely on the possession of raw physical and humanistic characteristics, and could easily be categorised as a disciplined, organised response to the onslaught of modernism at the turn of the $19^{\text {th }}$ century. Walvin (1975, p. 56) explained the evolution of British recreation as a result of modernism. In this evolutionary process, codified football was the cornerstone:

The contrast with pre-industrial leisure was stark. The new forms of leisure were as disciplined, regulated and even timetabled as the industrial society that spawned them. The irregular, undisciplined and violent recreations of an older society gave way to the stringency of more modern recreations.

This emergence of organised timetabling is another clear example of Hughson's (2009) disciplinary agenda reaching fruition, organising the British populace into a working week and re-creative weekend schedule.

\section{Football and Foucault.}

In the current paper, we employ the thoughts of French philosopher Michel Foucault as they provide what we see as the most agile means of mapping the workings and effects of power upon a body, in this case, that of a retired footballer. Throughout the early history of working association football, players are likened to slaves. However, Foucault (1991) identified that the meticulous control of the operations of the body that occur in the fiercely supervised context of a 'modern discipline' such as working football, differs significantly from slavery. The discipline that imposes a relationship of what Foucault would call docilityutility, is not based on repression or the appropriation of bodies (enslavement). Instead, through the regulation of time, space and movement, a body becomes exposed to effects of utility at least as great as slavery (Foucault, 1991). As it becomes more obedient, the body becomes more useful. In detail, footballers become 'docile bodies' as a result of their exposure to what Foucault (1991) called the techniques and instruments of discipline, 
coupled with living amongst the ever present 'panoptic' surveillance found in football (Giulianotti, 1999). Through these techniques and instruments, the cordoned body is rendered docile, and in the football context an individual becomes a 'docile footballing body' (Jones \& Denison, 2017). Foucault (1991, p. 136) observed that docile bodies are bodies that can "be subjected, used, transformed and improved" to achieve certain ends through a process of normalisation, and as a result, comply with the expected behaviours of a given space.

In short, the above is an accurate description of the obedient professional footballer. The body of a footballer endures most every organised structure or practice one could think of in order to render it docile, it is exposed to the workings of power through the imposition of discipline, and as a result it becomes efficacious in the sphere that it occupies (Jones \& Denison, 2017). Any docile body that fulfils its intended design acts to sustain dominant practices, attitudes and societal truths through its obedience; it is both an effect of and an agent in the maintenance of 'truth'. The practices that compose the work of professional football aspire to manipulate footballing bodies to conform to normalised ideals in order that their required 'function' might be achieved with maximum efficiency for the benefit of their employers: their football clubs (Jones \& Denison, 2018).

For the purposes of the present discussion surrounding the meaning of exercise in retirement for a former footballer (including how exercise might act as a leisure activity), it is important to note that the practices that contribute to the production of 'docile football bodies' in football almost exclusively involve the improvement, sustenance, positioning, and movement of a player's physical body - in short, they constitute what common parlance refers to as 'exercise'. For Foucault (1991, p. 162) exercise is not only an activity including the movement of the physical body but it is also "an element in the political technology of the body” that plays a significant role in the imposition of discipline: 
Exercise is a technique by which one imposes on the body tasks that are both repetitive and different, but always graduated. By bending behaviour towards a terminal state, exercise makes possible perpetual characterisation of the individual (p. 161).

When exercise is considered as such, it becomes apparent that almost every activity/exercise that a footballer engages in is intimately aligned with his ‘function' of being a footballer. Exercise, therefore, is complicit in the accruement of discipline imposed upon individuals by their footballing context. Repeated technical drills in training, the repetition of team shape the day before a match, strength and conditioning exercises, fitness testing, and on field performances, all of these are practices where discipline is 'exercised through exercise'. This normalised relationship between exercise, discipline, and work can lead to the elite footballer learning and internalising the phenomenon of exercise in a certain way. Importantly, exercise necessarily becomes inseparable from a footballer's vocational footballing ambitions. This relationship with exercise occurs within a football context sustained by a continued reliance upon a number of ubiquitous disciplinary techniques and instruments of surveillance. These are justified by historically engrained truths about what football is/should be (i.e., a means of disciplining young individuals into a performative function) - most of which are rooted in the modernist ethos of controlling the movement of the physical body. The quest to produce ‘docile footballing bodies' that defines current practice and development in football is dangerously unbalanced due to its historical and contemporary reliance upon intimidation, conformity, and control (Jones \& Denison, 2018). This is a problem for players during their careers (Giulianotti, 1999) but, as we consider more intimately in what follows, this also has significant implications for how a retired player relates to exercise not as work, but as a leisure pursuit. 


\section{Exploring Exercise in Sport Retirement through Narrative Representation}

Up to this point, studies that have considered exercise in retirement from sport have been conducted almost exclusively from a bio-medical or psychological perspective, and have identified the physical and mental benefits of regular exercise. Unsurprisingly, they promote continued exercise as key to lifelong health amongst retired athletes (Witkowski \& Spangenberg, 2008). Although it is hard to argue that these findings provide sensible advice, one might argue that positivist and post-positivist approaches to researching exercise, in preserving the objective stance of the researcher, fail to provide in-depth interpretations of the meaning of exercise for various populations. The objective study of the exercising body has turned sportspeople into objects to be monitored, improved, and controlled for a purpose. Furthermore, the majority of sport and exercise research has framed exercise as a regulated, sanitised, and disembodied practice (Jones \& Toner, 2016).

At the turn of the century, a wave of creative analytical practices emerged and inspired several new ways of writing about the body (Richardson, 2000). This development included a shift towards the use of narratives to represent many of the experiences associated with sport and the moving body (Tsang, 2000). This movement towards creative means of representation could be described "as an emotional reaction against positivist dogma” (Denison, 2016, p. 8). For example, Denison (1999), as well as Sparkes, (1998, 1999), Tiihonen (2003), and Tsang (2000), produced several evocative narratives to highlight various difficulties experienced when negotiating the pressures and transitions of elite sport, including detailing the moments of moving towards and living with their 'post-athletic' bodies, selves, and lives. For example, Denison (1999) in 'Boxed In' described the intensity of frustration and emotional pain associated with an unavoidable impending cessation of an athletic career. In, 'Athletic identity: An Achilles' heel to the survival of self', Sparkes (1998) revealed the acute challenges faced when an athletic career is disrupted by illness. Similarly 
in 'The fragile body-self', Sparkes (1999) sensitively outlined the connections between his chronic back pain and his insecurities and anxieties surrounding all aspects of his life. In 'Body Talks', Tiihonen (2003) highlighted the intersection of health, football, and post-career exercise behaviours, revealing how all these personal factors are intertwined in the remainder of an athlete's life. In 'Let me tell you a story', Tsang (2000) also used a narrative approach to explore the possibilities for hybridity and ambiguity of identity whilst residing within the normalising project of high-performance sport. Tsang's (2000, p. 57) ambition was to use narrative to bring the reader "in contact with her athletic identity in an academic venue" as she attempted to balance her elite rowing career with her postgraduate studies. She observed that, unlike traditional research approaches, a narrative approach allowed for ambiguities to surface and for contradictions to co-exist as she told her stories from this rather unique perspective.

In many ways these narratives were engaging and were a breath of fresh air to the heavily positivist sports science climate. Building on Denison (2016), however, we believe that despite breaking important ground, these stories, while "increasing our sensitivity to the suffering of others who are unfamiliar to us” (Duncan, 1998, p. 97), perhaps did not consistently evidence the connection between lived experience and theoretically informed analysis. To achieve this theoretical connection, Denison (2016) suggested that those who engage in narrative writing (including those who write about exercise) need to:

Acknowledge how as scholars, not just writers, if we want our narratives to do justice to our training as qualitative social scientists... we need to bring social theory into accounts in more obvious ways; we have to find ways to blend rich description with thick analysis (p. 9).

Like Tsang (2000), we see the narratives presented in this paper telling a story from a particular vantage point: that of a retired athlete (the first author) versed in social 
(Foucauldian) theory. Through this perspective, it is our aim to reveal not only the complex emotions associated with exercise in sports retirement, but more importantly the relations of power at play and their potential implications and effects. We hold to the notion that narratives, when well performed can not only 'show' the reader another's perspective (Gearity, 2014), but also provide an ‘analytical insight' (Anderson \& Austin, 2012) than can help the reader go beyond empathy and can emphasize change, contingency, context, improvisation, and struggle (Denison, 2016). Moreover, we believe that when narrative and theory intertwine, the resultant text can challenge the reader to think differently and to consider the complexities of embodied living (Denison, 2016).

\section{Research Process}

This paper is written as an analytic auto-ethnography (Anderson, 2006), intended to use expressive prose to bring some of the personal complexities of exercising after retirement from football to life. For Anderson, when conducting an analytic auto-ethnography, the author needs to be a 'full member' of the sub-culture under investigation, must engage in reflexive and revelatory analysis, and be committed to theoretical analysis. As mentioned, the first author is a former footballer, and therefore qualifies as a full member of the sub-culture under study. We feel that the included narratives and accompanying analysis are highly reflexive, and due to the creative means of representation adopted, revelatory in their nature. Furthermore, rather than left to stand alone as they would in an evocative auto-ethnography, the stories included below are analysed by experienced post-structuralist researchers using a Foucauldian theoretical framework. For these reasons, we believe the current research meets Anderson’s (2006) criteria as an analytic autoethnography.

Ronkainen et al., (2018) recently explored the relationship between identity and running for leisure amidst periods of transition using a narrative methodology. However, to our knowledge there are no current studies that have used a narrative, auto-ethnographic or 
otherwise, to consider retired football players' experiences of attempting to exercise for leisure. Following the first author's football career, he has had significant trouble developing and maintaining a 'balanced' relationship with exercise, and with that his body weight and 'good' health. Unencumbered by the responsibilities 'hardwired' into him during his period within elite football, he ceased to engage in the excessive exercise common to sportspeople and enjoyed the aspects of life he had sacrificed. However, in doing so, like many retired footballers from several codes, he has put on weight (Belson, 2018). In response to this, he employed the exercise techniques and skills acquired during his working football career to attempt to recover the previous version of his 'acceptable’ physical body. Although fleetingly, he sometimes achieved this goal. So began his on-going challenge to develop a new meanings for his exercise outside of 'being a footballer.'

The stories we include below were written by the first author on various occasions following the cessation of his football career in 2008. He composed each narrative following an independently initiated run/jog that he then archived into a chronological collection of 'post-football exercise stories'. We selected the four narratives presented here on the basis that they informed the first author's attempt to make sense of the changes in his orientation to exercise as an aspect of his leisure time. As well as the location, we include the date of each story to provide the reader with some temporal context.

\section{Riverbend Road, Edmonton, Alberta, Canada - Winter 2008. \\ Running Free}

As I take the first pounding steps on the hard, cracked concrete, the faintest whisper of mist greets my quickening breath. Here we go again. We're running.

The first part of a run is always the same. Silent negotiation and bartering between multiple voices. How far am I going to go? What do I feel like tonight? Let's just do half the route. 
No, let's go an extra mile...In this jumbled phase, the treaty is drawn up. Silently each voice is appeased, obeyed, or thwarted.

A decision is reached...and I press onwards.

Tonight seems alike to every other. I'm out here in the crisp, chilling cold because I should be.

A strong, dominant voice inside me tells me I should be here. In the card game that takes place within me, this voice typically holds more cards than any of the others. I've been dealing him a flush draw for years and years, and he still tries to splash the pot. He's the reason I'm out here in minus 20, he’s the reason I love this, and the reason I hate this. But this night is strange, this night is different.

There is something in the air, something in the breeze. I slow my pace. Gently bobbing along I chuckle. As I chuckle, a new smile spreads its way through the first layer of trickling sweat forming on my stubbled face. Why not, I think? Why not?

I know exactly what I’m going to do. But there is no reason why. I just want to.

With a few high, bounding paces, I ignite and then explode. I explode into a fierce release. I start off low then kick on hard, flying forward, rushing past lampposts and bus stops along the empty and lonely street. I carry my gnarled old legs with my strong, faithful arms until the explosion ends. Short stuttering steps jam into the sidewalk and bring me to a stop. My hands fall to my knees. As my heaving lungs harvest the stinging air, my heart rushes. Still I smile. God that felt good.

I set off again, smiling, bobbing along. That explosion wasn’t for me, and it wasn’t for him. It just was.

Why did it have to be for anyone? I will serve this voice no longer; there are others. Voices that let me run free. 
Parksville Beach - Vancouver Island, British Columbia, Canada - August 2009. Jogging not Running

My heart rises with the sun as pink melts into crimson and I turn to the shore. Cold cheeks are warmed by the growing rays and the steady euphoria of adrenaline.

I run.

I run to the shoreline horizon and my lungs begin to burn. I strive to maintain strong steps but my euphoria gradually turns to pain. This is a pain I feel I have always known. But...it wasn't always there.

With the pain come the doors. Doors long since closed. Yet the thumping blood in my veins swings them open, exposing glimpses of past glory. As my pace quickens I envisage new stories and new victories. I believe. I could do that again.

As I reach the still shore, reality encroaches into my fantasy, bringing me back to earth. I can run no further. Chest heaving, I stand exhausted and finished. Emotionally broken, physically tired.

My escaping breath flows fast as mist before me, blurring a magnificent mountain view. I pause. A beautiful silence consumes me as I rest.

Solace.

Absolute solace.

Time to go.

I turn away from the ocean and again the rising sun warms my neck and back. Blazing sunlight illuminates my old footsteps, moulded into the soft sand. As I lightly jog back I travel alongside my path. I look at the path with no malice, and for the first time, no regrets. Instead, I contemplate its existence with a fierce pride. I resolve never again to open those doors, but to never let their memory be erased. 
Smiling, I raise my head and jog on. Moving away from the gentle waves, I leave behind me beautiful, fresh footprints in the sand.

During their career, working footballers are "excluded from alternative ways of using their physical body” (Jones \& Denison, 2017, p. 936). Moreover, as we noted at the outset of this paper, a disciplined 'docile' athlete works hard to stifle non-functional exercise experiences in order to comply with the normalised expectation that exercise is exclusively a preparatory or performative endeavour. In retirement, it is undoubtedly true that the legacy of docility has significant effects; we are firm that this is one of our key points. For example, in Jogging not Running, the first author reveals how through the embodied act of running, certain physical movements automatically evoked memories and re-emphasised 'hard-wired' connections established through a life of exercise married to discipline: 'the thumping blood in my veins swings the doors open, exposing glimpses of past glory'. However, it is also true that in certain ways, these effects do naturally wane as the disciplinary techniques and instruments directly imposed upon a retired player begin to lessen. What we believe these first two narratives suggest is that while the relationship between exercise and discipline may always be a background feature of a retiree’s exercise, as the direct influence of discipline begins to lessen as an individual inhabits their 'new post-sport reality', something begins to change. We are trying to show that perhaps the relative freedom of retirement does permit a former player to exercise their body in new and different ways. As the first author noted at the end of Running Free, on this occasion he experienced exercise instinctively rather than as a means of serving a dominant, disciplinary 'voice' in an attempt to 'run free'. He now feels able to create running experiences and moments that 'just are' and are not rationalized by a functional disciplinary purpose. Perhaps in re-orientating oneself to exercise, a retired player is given licence to enjoy an exercise experience based upon the joy of speed and movement. 
In addition, this may be an experience no longer explicitly connected to a 'function' as would be expected of an in-situ ‘docile footballing body’ (Jones \& Denison, 2017).

Hawrelak Park - River Valley, Edmonton, Alberta, Canada - March 2010. Feeling Good

Sunlight staccatos through overhead branches and touches the cool, still ravine. My heart thumps in my chest and I taste and feel salt in my eyes. I glance at the stopwatch on my GShock. I have run a strong time.

I allow myself a satisfied smile.

As the pace of the blood rushing through my veins subsides, the music flowing from my iPod drifts into my consciousness. It is a beating drum that has been my accomplice and my friend. I am accustomed to its steady beat. Today in the crisp air, amongst the freshly fallen leaves, the drum has driven me forward once more.

As I slowly walk up the gradual incline of the ravine boardwalk, I notice the odd leaf scattered across the weathered wooden beams. I breathe in the delicious rays of sun that break through with accumulating strength as the tree line fades away. I am humbled by the clean light. A crystal blue, cloudless sky is revealed. I completely stop for a second and look up. It is so beautiful.

A new song clicks on.

A gentle piano riff sets the scene, and the huge guitars explode in crescendo. With my iPod set to shuffle, I cannot believe that this song has come on. The lyrics capture my feelings at this moment so completely and resonate deeply with the place where my patched-up soul gently rests.

"Sun in the sky, you know how I feel..."

The familiar warmth of a tear fills my eye, and I jog on as the music continues...

“It’s a new dawn, it’s a new day, it’s a new life for me...And I’m feeling good”. 
A first reading of Feeling Good positively points to the truth that the first author's football career has taught him how to 'exercise well'. It seems to suggest that he can be 'welldisciplined' and that logically he is therefore destined to continue 'exercising well' in retirement. He knows how to marry his movement to the measurement of time, as well as the rhythmical metronomic timing of a beating drum on an Apple device. In other words, he is capable of exerting the necessary control to 'discipline the body as a possession of the self' (Lupton, 2012) in a quest to avoid becoming an ‘unacceptable body’ (Chase, 2008). In discussing the relationship between docility and utility, Foucault (1991) was clear that power must not simply be considered as repressive but should always be considered as a potentially productive phenomenon. It is hardly unsurprising, therefore, that many elite athletes or 'retired docile bodies’ are apparently able to transfer their aptitude for exercise from their sport careers into other exercise projects as part of their leisure time.

Along these lines, research from Carless and Douglas (2009) moved the field of sports retirement forward by identifying how athletes might shed their limiting attachments to a ‘performance based narrative’ during their transition away from sport. By focusing upon the actions of the individual within social relations, (in a similar fashion to Frank’s (1995) work regarding the re-storying of change), these authors identified how athletes can focus upon diversifying their narrative resources, and in so doing, 're-story' their experiences of life after leaving sport in a positive fashion. Carless and Douglas suggested that this 're-storying' process enables sportspeople to experience a more manageable transition away from their sporting role. As a result, the idea of encouraging athletes to develop alternative, less linear narratives of self during and after their careers has become well-recognised as helpful means of preparation for and management of sports retirement (Cavallerio, Wadey, \& Wagstaff, 2017). 
In the context of the current paper, we have attempted to show that when attempting to 're-story' their post-athletic relationships, with regards to their exercise, because they often have little other option, athletes commonly do so in a way that is congruent with their abilities and resources. For example, because of the productive nature of discipline, retired athletes usually perceive one fruitful legacy of their careers to be a propensity to exercise in a disciplined manner. They believe they have an 'inside track' or advantage when it comes to meeting the demands of any new exercise responsibilities. The former athlete may feel that their almost universally celebrated discipline (Heikkala, 1993) affords them an advantageous foothold that allows them to reach their newly understood post-retirement 'exercise goals'. A former 'docile athlete', unsurprisingly, often comes to believe that because of their past experiences, in their new life, they are well-equipped to solve the 'reflexive problem for the self' that neo-liberalism’s shift in power relations has designated the exerciser (Lemke, 2001).

In Feeling Good, the first author’s euphoria, although apparently ‘new found’, could be read as connected to his ability to recruit a timepiece and the rhythmic beat of a drum. In doing so, perhaps he is returning to/mining a skill-set derived from his previous relationship with exercise as a disciplinary mechanism. The 'liberated’ retired player meets the project of 're-storying' their relationship with exercise equipped with an aptitude to exert 'disciplined behaviour' upon their body. Embedded logic now dictates that they can quite freely and manageably ‘exercise autonomously’ and, in doing so, fulfil their role as a 'good neo-liberal citizen'. The athlete is successfully 're-storying' themselves in line with the alternative stories available within the socio-cultural environment they now find themselves within (Carless \& Douglas, 2009). However, and this is where we believe our Foucauldian-informed point of view comes into play, are they doing so at their own peril? Our argument is that, in 
contrast to accepted wisdom, this is a dangerous trajectory for the retired athlete to internalise.

In Feeling Good the first author is seemingly performing the "necessary and on-going life project” of re-storying his 'self' (Carless \& Douglas, 2009, p. 64). It appears he is experiencing a moment of epiphany, allowing cathartic progression into a new, more wholesome relationship with exercise post-football. These experiences seem real, they were apparently re-creative, and they clearly were transformational - but several questions remain unanswered. Is it as simple as telling a new story about oneself to become happy? Are retired athletes to trust the transformative promise of 're-storying' their selves? Is this an appropriate long-term strategy? While we acknowledge that the idea of re-storying can be helpful, what concerns us is the expectation that athletes must do this themselves. Focusing upon the individual dictates that in order to manage safe passage into the multiple aspects of retirement from sport, said individual must resist (and manipulate for their own means), the multiple relations of power in their new circumstance. However, we are concerned that this individualcentred approach renders the calculation and observation of relations of power as secondary, or even ignored, at the expense of concentrating upon an individually piloted project. We argue that invested parties need to think more critically, and with more than a cursory eye on the socio-cultural environment retired athletes find themselves occupying, as they begin to reimagine how to use their leisure time to exercise.

An alternative reading suggests that the scenario presented in Feeling Good is the first step being taken by a retired athlete into a trap that precludes them from developing alternative meanings for their exercise. By approaching the self-constitutive practices their neo-liberal context demands of them (Lemke, 2001), and armed with an historical propensity for discipline, we argue that the retired athlete is further averting their potential to develop alternative meanings for their exercise. These could include meanings that acknowledge the 
limitations of an evolving body, that focus more on developing bodily awareness and movement within one's natural surroundings, allowing one to forget one’s social background (Nettleton, 2013). We are concerned that retired athletes, who internalise the neo-liberal pressures of their new space and revert to their past docility, become unable to see/experience exercise as anything other than a means to re-create a newer (if more adaptable) version of their old athletic self. We argue that this leaves the former athlete inflexible in the face of future obstacles such as aging, changes in responsibility, parenthood, or the negotiation of physical or mental illness. We also argue that as an individual becomes further and further removed from what was possible as a single-minded, disciplined athlete, a 're-storying' logic (Carless \& Douglas, 2009), although appealing, may not be the most compatible for the unpredictable and fluid challenges of life. Specifically, we are concerned that this includes learning how to move one's body in a way that is not self-disciplinary, or linked to the norms associated with an athlete’s previous sporting role.

It is hard to argue against the fact that, in retirement, many ex-athletes continue to exercise 'well' as they once did - yet that is not our goal. Instead, here, we use our Foucauldian reading to warn that these individuals may well experience significant challenges associated with developing new or different exercise relationships as ex-athletes relationships where using exercise is no longer intimately connected to exerting disciplinary power upon one's physical body. The assumption that because of their 'aptitude for discipline', retired athletes experience a seamless transition into managing new or alternative long-term exercise relationships as one among many of their leisure time pursuits is worth questioning. What happens when the context of the game, winning, youth, and the hope of 'making it' are removed and retired athletes are confronted with the necessity of bringing new meaning to exercise over the long term? What are the long-term challenges that arise in the new and different spaces and phases of life? 


\section{Swanland Road - Hessle, East Riding of Yorkshire, England - June 2015.}

\section{Fields of Gold}

Late evening sunshine bounces off the sunroof of a stationary car directly into my eyes. One foot after the other, I pass by the red brick houses on the edge of town. I drag myself up the 'hill' of Swanland Road, plodding on towards the wheat field.

Five minutes into my run and I am so stiff I can hardly move. An assassin twists an invisible blade into the small of my back and my calves scream, 'No!' I am in genuine pain. I stop to stretch and catch my reflection in a conservatory window. What a joke. You fat bastard. How did you let this happen?

But I want to run. I need to run. I am too heavy.

I look at my watch, glance back shamefully at the meagre distance covered and turn to hobble onward up the road to the farmer's field. I am literally running like an old man. I want to abort this run and this feeble quest for yesteryear. I want to abandon this body. I want to give up and go home. Give up and go home. But I am not allowed.

I am required to run, to lose weight, to feel good, to be healthy, to move on.

I finally make it to the farmer's gate and squeeze through onto a hard and chalky path that runs alongside the field. I finally work up something of an acceptable pace, plodding along beside the scratchy golden stalks of wheat. Mercifully, in this fleeting moment of resolve, I have the field to myself.

But soon, after a pitifully short space of time, the pain returns and my breathing lags. I slow to a saunter, double over and hang on my knees. I walk for a while, surveying the countryside in the twilight. I check that no one is around. I crumple to the dusty floor, laid bare. Dirt sticks to my sweaty legs. After a while, with some effort, I drag myself to my feet and set off again. 
As the vivid rays of a gorgeous orange sunset descend, I repeat this stop-start, pathetic attempt at a run until I can abide no more.

Head bowed, I eventually come to a standstill.

I give up. I go home.

In Fields of Gold, the first author is no longer a 'young man', and is now a husband, a father, and a provider. In this narrative he is experiencing a deep sense of frustration because, later in his retirement, his exercise behaviours and physical characteristics have become incompatible with the contemporary expectations dictated by his new social circumstances. This discrepancy has become a source of shame and low self-worth as he still feels duty bound to meet these standards. At this juncture, it is important to note that as a result of his academic training and his exposure to Foucault's cache of concepts, the first author came to question many of the truths that sustained his meaning and purpose for exercise. He began to realise that, as an active player, he was expected to comply with defined exercise patterns as a member of a productive and efficient body swept along by the operations of his football club’s ‘composition of forces’ (Foucault, 1991). As a footballer, exercise was scheduled for him and was not something he needed to find time for in his leisure. The first author also came to understand that in retirement he escaped football's normalising gaze and entered into new social realms and experienced new functions and relationships. He also began to appreciate that broader society had now taken on the predominant role of exercising power upon him, albeit in a "diffused, multiple, polyvalent way throughout the whole social body" (Foucault, 1991, p. 208).

Lupton $(1997,2016)$ has explained that for Foucault, different eras privilege different ideas and discourses about how citizens should conduct themselves. Drawing upon this Foucauldian notion, she explained how in contemporary western cultures predominant 
discourses operate to frame a 'good citizen' as one who is responsible, capable, and selfregulated in the pursuit of happiness, health, productivity and wellbeing. Lupton also observed that in order to comply with these contemporary societal expectations, individual members of society are encouraged by widely publicised bio-medical norms surrounding the body (Lupton, 1997), and an emphasis upon an ‘ideal of re-invention’ to repeatedly engage in practices that transform and normalise their physical bodies (Lupton, 2016).

In order to comply with societal expectations, individuals are to take responsibility for themselves, including their leisure and exercise practices, especially as they relate to health (Hervik \& Thurston, 2016). In fact, a strong rationale used to support youth sport is that it will foster a host of 'lifelong' positive attitudes towards sport and exercise in children. This includes appreciating the value of exercise and sport so that one might proactively avert inactivity and any subsequent physical or mental ill health (Holt, 2016). Findings from sports medicine and science also serve to firmly situate lifelong exercise as an important nonpharmacological intervention or 'key lifestyle medicine’ (Lee et al., 2017). In addition, research exists that evidences physical activity as able to decrease incidents of heart disease, type two diabetes, hypertension, stroke, as well as a range of cancers (Katzmarzyk \& Janssen, 2004), and that the maintenance of aerobic capacity and skeletal muscle strength by lifelong activity delays biological ageing and premature death (Roberts \& Barnard, 2005). Interestingly, research also suggests that elite athletes are more susceptible to chronic illness if they cease exercising, and that the effect of inactivity for the retired athlete may be significantly pronounced, including changes to insulin sensitivity, plasma lipid and body composition (Booth \& Roberts, 2008).

Around the time Fields of Gold was written the first author felt that he had to learn how to exercise like most others, amidst a contemporary western culture underpinned by a strong neo-liberal discourse of personal responsibility for health, and a bio-medical discourse 
that promotes being fit, healthy, and including exercise as part of one's life as an essential countermeasure for ill-health. The point we are making in Fields of Gold is that he did not find this an easy transition at all. The first author's grasp of Foucault's theory left him unwilling to accept exercise as a technique for normalisation and left him frustrated at being unable to forge his own 'new meaning for exercise'. Crucially, this included developing any meaning separate to those permitted by normalised societal expectations surrounding exercise. While conventional wisdom suggests that he is now 'free' from his sporting responsibilities, his Foucauldian lens left him reluctant to accept the 'truth' that he should now exercise as an autonomous, atomised actor searching for health, productivity, and happiness (Lupton, 2016). Put another way, in his mind he is now unwilling to accept that he need once more become a docile body - this time in a new, broader social context. Instead, like the participants in Crocket's (2014) study, he began to problematise the 'truth games’ that define exercising in retirement from sport. The experiences regaled in Fields of Gold try to show that as a result (for a time at least), he was left marooned and confused as to how to proceed, unwilling to engage in what he identified as the 're-disciplinary' bodily practices being prescribed as best practice for the exercising post-athlete. Fields of Gold emphasises how he has been left awakened, but also de-stabilised, longing for ways to learn new meanings for exercise.

\section{Conclusion}

In compiling this piece of narrative research, we were cautious to avoid writing a 'phoney, feel-good piece' (Denison, 2002) that over simplified and obscured the complex realities of a former elite footballer's relationship with the 'meaning of exercise': the contradictions, tensions and nuances. Like Tsang (2000), we believe in the potential of narratives to illuminate aspects of sport and exercise but importantly, only when this means of representation is adopted alongside a well-informed social analysis (Denison, 2016). To 
this end, we have tried to use the first author's exercise stories to point towards the idea that in retirement, former athletes’ docility, while seemingly advantageous, can also be a significant obstacle to developing alternative meanings for exercise, including as a potential re-creative or leisure activity that can become meaningful and important in its own right.

What is more, these narratives purposefully problematise the games of truth that frame how retired athletes 'should' engage with exercise as a component of their 'recovery' from a life of sport. We have attempted to disturb the notion that 'best practice' for retired athletes should involve them engaging in a 're-storying' of themselves. We argue that encouraging them to do so adopts a logic that is impervious to the fact that rather than being progressive as it claims, instead pushes them backwards to their old subjectivities and docility in order to acquiesce with the new expectations of exercising in a particular way foisted upon them by contemporary neo-liberal expectations of health and wellbeing.

The narratives presented in this paper have also tried to show that from a Foucauldian perspective, power, mobilised by contemporary norms surrounding exercise and health, is operating upon the first author. This disciplinary power normalises how the first author understands the desirable state of the human body and seeks to facilitate the production of him as a docile body in western society (Lupton, 1997). This is a clear example of how neoliberal thought and practice are directly implicated in shaping the way health and leisure are promoted (Ayo, 2012). In particular, the latter story, Fields of Gold, highlights the tension experienced by the first author who, as a thoughtful Foucauldian thinker, is precluded from developing/creating a relationship with exercise in an alternative way to those prescribed/allowed by the relations of power that have determined his past, or those that define his current reality. This tension is evidenced by his allegiance to his 'quest for yesteryear', and his desire to run at an 'acceptable pace', that runs alongside his parallel recognition that he is 'not allowed' to give up on the pursuit of exercise induced physical 
fitness. As an exercising body he is 'required to run, to feel good, to be healthy', and, because of his past relation to disciplinary power, he cannot escape the nagging belief that he should be able to do so. We have attempted to show that this has not been the case and that the first author has struggled to reach a point where his exercise would constitute a leisure activity where he is able to think and act in ways that indicate a concern and focus on 'himself' above his compliance to established norms. Of course such an ethic is not easy to adopt and requires continual self-work, or what Foucault referred to in his later work concerning the technologies of the self, the development of a new telos (Markula \& Pringle, 2006). But perhaps this point is not far away for the first author. Perhaps he is close to inventing his own understanding of how to become a healthy moving body after further problematizing what he currently believes exercise and leisure 'should' mean in his life. 


\section{References}

Anderson, L. (2006). Analytic auto-ethnography. Journal of Contemporary Ethnography, 35, 373-395.

Anderson, L., \& Austin, M. (2012). Auto-ethnography in leisure studies. Leisure Studies, 31(2), 131-146.

Avner, Z., Denison, J., \& Markula, P. (2019). “Good athletes have fun”: A Foucauldian reading of university coaches' use of fun. Sports Coaching Review, 8, 43-61.

Ayo, N. (2012). Understanding health promotion in a neoliberal climate and the making of health conscious citizens. Critical Public Health, 22, 99-105.

Blinde, E., \& Stratta, T. (1992). The sport career death of college athletes: Involuntary and unanticipated sport exits. Journal of Sport Behaviour, 15, 3-20.

Booth, F., \& Roberts, C. (2008). Linking performance and chronic disease risk: Indices of physical performance are surrogates for health. British Journal of Sports Medicine, 42, 950-953.

Carless, D., \& Douglas, K. (2009). 'We haven't got a seat on the bus for you' or 'all the seats are mine’: Narratives and career transition in golf. Qualitative Research in Sport and Exercise, 1, 51-66.

Cavallerio, F., Wadley, R., \& Wagstaff, C. (2017). Adjusting to retirement from sport: narratives of former competitive rhythmic gymnasts. Qualitative Research in Sport and Exercise, 9, 533-545.

Chase, L. F., (2008). Running big: Clydesdale runners and technologies of the body. Sociology of Sport Journal, 25, 130-147. 
Crocket, H. (2014). "I had no desire to be having this battle with this faceless man on the soccer field anymore”: Exploring the ethics of sporting retirement. Sociology of Sport Journal, 31, 185-201.

Cruikshank, B. (1999). The will to empower: Democratic citizens and other subjects. New York: Cornell University Press.

Denison, J. (1999). Boxed in. In A. C. Sparkes and M. Silvennoinen (Eds.), Talking bodies: Men’s narratives of the body and sport (pp. 29-36). Jyväskylä, Finland: SoPhi, University of Jyväskylä Press.

Denison, J. (2002). Writing a “true” sports story. Auto/Biography, 10, 131-137.

Denison, J. (2007). Social theory for coaches: A Foucauldian reading of one athlete's poor performance. International Journal of Sports Science and Coaching, 2, 369-383.

Denison, J. (2016). Social theory and narrative research: A point of view. Sport, Education and Society, 21, 7-10.

Duncan, M. (1998). Stories we tell ourselves about ourselves. Sociology of Sport Journal, 15, 95-108.

Fleuriel, S., \& Vincent, J. (2009). The quest for a successful career change among elite athletes in France: A case study of a French rugby player. Leisure Studies, 28(2), 173188.

Foucault, M. (1991). Discipline and punish: The birth of a prison. London, England: Penguin Books.

Frank, A. (1995). The wounded storyteller: body, illness and ethics. Chicago University Press: Chicago. 
Gearity, B. (2014). Autoethnography. In L. Nelson, R. Groom \& P. Potrac (Eds). Research methods in sports coaching (pp. 205-216). London, England: Routledge.

Giulianotti, R. (1999). Football: A sociology of the global game. London, England: Polity Press.

Heikkala, J. (1993). Discipline and excel: Technologies of self and body and the logic of competing. Sociology of Sport Journal, 10, 397-412.

Hervik, A., \& Thurston, M. (2016). 'It’s not the government's responsibility to get me out running $10 \mathrm{~km}$ four times a week' - Norwegian men's understandings of responsibility for health. Critical Public Health, 26(3), 333-342.

Hickey, C., \& Kelly, P. (2008). Preparing not to be a footballer: Higher education and professional sport. Sport, Education and Society, 4, 477-494.

Hill, P., \& Lowe, B. (1974). The inevitable metathesis of the retiring athlete. International Review for the Sociology of Sport, 9, 5-29.

Holt, N. (2016). Positive youth development through sport. London, England: Routledge.

Hughson, J. (2009). The working class and the making of sport. Sport in Society: Cultures, Commerce, Media, Politics. 12, 53-68.

Jones, L., \& Denison, J. (2018). A socio-cultural perspective surrounding the application of GPS technology: Some suggestions for the Strength and Conditioning coach. Strength and Conditioning Journal, 40(6), 3-8.

Jones, L., \& Denison, J. (2017). Challenge and relief: A Foucauldian analysis of retirement from football. International Review for the Sociology of Sport, 52 (8), 924-939. 
Jones, L., \& Toner, J. (2016). Surveillance technologies as 'instruments of discipline' in the elite sports coaching context: A cautionary post-structural commentary. Sensoria, 12(2), 13-21.

Katzmarzyk, P., \& Janssen, I. (2004). The economic costs associated with physical inactivity and obesity in Canada: An update. Canadian Journal of Applied Physiology, 29, 90115.

Lee, D., Brellenthin., Thompson, P., Sui, X., Lee, I., \& Lavie, C. (2017). Running as a key lifestyle medicine for longevity. Progress in Cardiovascular Diseases, 60, 45-55.

Lemke, T. (2001). 'The birth of bio-politics': Michel Foucault's lecture at the Collège de France on neo-liberal governmentality. Economy and Society, 30(2), 190-207.

Lupton, D. (1997). Foucault and the medicalisation critique. In A. Peterson \& R. Bunton (Eds). Foucault, health and medicine (pp. 94-112). London, England, Routledge.

Lupton, D. (2012). Medicine as culture: Illness disease and the body. ( $3^{\text {rd }}$ ed.). London, England: Sage.

Lupton, D. (2016). The quantified self. Cambridge: Polity Press.

Markula, P., \& Pringle, R. (2006). Foucault, sport, and exercise: Power, knowledge, and transforming the self. London, England: Routledge.

McMahon, J., Penney, D., \& Dinan-Thompson, M. (2012). Body practices - exposure and effect of a sporting culture: Stories from three Australian swimmers. Sport, Education and Society, 17, 181-206.

Nettleton, S. (2013). Cementing relations within a sporting field: Fell running in the English Lake District and the acquisition of existential capital. Cultural Sociology, 7, 196-210. 
Richardson, L. (2000). Writing: A method of inquiry. In N. Denzin \& Y. Lincoln (Eds). Handbook of Qualitative Research ( $2^{\text {nd }}$ ed.). London: Sage.

Roderick, M. (2006). The work of professional football: A labour of love? London, England: Routledge.

Roberts, C., \& Barnard, R. (2005). Effects of exercise and diet on chronic disease. Journal of Applied Physiology, 98, 3-30.

Ronkainen, N. J., Shuman, A., Ding, T., You, S., \& Xu, L. (2018). 'Running fever’: Understanding runner identities in Shanghai through turning point narratives. Leisure Studies, 37(2), 211-222.

Sparkes, A. C. (1998). Athletic identity: An Achilles' heel to the survival of self. Qualitative Health Research, 8, 644-664.

Sparkes, A. C. (1999). The fragile body-self. In A. C. Sparkes \& M. Silvennoinen (Eds.), Talking bodies: Men’s narratives of the body and sport (pp. 51-74). Jyvaskyla, Finland: SoPhi, University of Jyväskylä Press.

Tracey, J., \& Elcombe, T. (2004). A lifetime of healthy meaningful movement: have we forgotten athletes? Quest, 56, 241-260.

Tsang, T. (2000). Let me tell you a story: A narrative exploration of identity in highperformance sport. Sociology of Sport Journal, 17, 44-59.

Walvin, J. (1975). The people's game: A social history of English football. London, England: Allen Lane. 